\title{
Altered skeletal muscle fatty acid handling is associated with the degree of insulin resistance in overweight and obese humans
}

\author{
Birgitta W. van der Kolk ${ }^{1}$. Gijs H. Goossens ${ }^{1}$. \\ Johan W. Jocken ${ }^{1} \cdot$ Ellen E. Blaak ${ }^{1}$
}

Received: 9 May 2016 / Accepted: 12 August 2016 / Published online: 15 September 2016

(C) The Author(s) 2016. This article is published with open access at Springerlink.com

\begin{abstract}
Introduction/hypothesis Disturbances in skeletal muscle fatty acid (FA) handling may contribute to the development and progression of whole-body insulin resistance (IR). In this study, we compared fasting and postprandial skeletal muscle FA handling in individuals with varying degrees of IR.

Methods Seventy-four overweight/obese participants (62 men) were divided into two groups based on the HOMA-IR median (3.35). Fasting and postprandial skeletal muscle FA handling were determined by combining the forearm muscle balance technique with stable isotopes. $\left[{ }^{2} \mathrm{H}_{2}\right]$ palmitate was infused i.v. to label VLDL-triacylglycerol (VLDL-TAG) and NEFA in the circulation, whereas [U- $\left.{ }^{13} \mathrm{C}\right]$ palmitate was incorporated in a high-saturated FA mixed-meal labelling chylomicron-TAG. Skeletal muscle biopsies were taken to assess intramuscular lipid content, fractional synthetic rate (FSR) and the transcriptional regulation of FA metabolism.

Results Postprandial forearm muscle VLDL-TAG extraction was elevated in the high-IR vs the mild-IR group $\left(\mathrm{AUC}_{0-4 h}\right.$ : $0.57 \pm 0.32 \mathrm{vs}-0.43 \pm 0.38 \mathrm{nmol}[100 \mathrm{ml} \text { tissue }]^{-1} \mathrm{~min}^{-1}$, respectively, $p=0.045$ ). Although no differences in skeletal muscle TAG, diacylglycerol, NEFA content and FSR were present between groups, the high-IR group showed increased saturation of the intramuscular NEFA pool $(p=0.039)$. This was accompanied by lower muscle GPAT1 (also known as GPAM) expression $(p=0.050)$.
\end{abstract}

Birgitta W. van der Kolk

b.vanderkolk@maastrichtuniversity.nl

1 Department of Human Biology, NUTRIM School of Nutrition and Translational Research in Metabolism, Maastricht University Medical Center ${ }^{+}$, PO Box 616, 6200 MD Maastricht, the Netherlands
Conclusions/interpretation Participants with high-IR demonstrated increased postprandial skeletal muscle VLDL-TAG extraction and higher saturation of the intramuscular NEFA pool vs individuals with mild-IR. These data support the involvement of disturbances in skeletal muscle FA handling in the progression of whole-body IR.

Keywords Chylomicrons $\cdot$ Insulin resistance $\cdot$ Lipid metabolism $\cdot$ Skeletal muscle $\cdot$ VLDL

$\begin{array}{ll}\text { Abbreviations } \\ \text { DAG } & \text { Diacylglycerol } \\ \text { FA } & \text { Fatty acid } \\ \text { FSR } & \text { Fractional synthetic rate } \\ \text { IFG } & \text { Impaired fasting glucose } \\ \text { IGT } & \text { Impaired glucose tolerance } \\ \text { IR } & \text { Insulin resistance } \\ \text { LPL } & \text { Lipoprotein lipase } \\ \text { MUFA } & \text { Monounsaturated fatty acid } \\ \text { PL } & \text { Phospholipid } \\ \text { PUFA } & \text { Polyunsaturated fatty acid } \\ \text { Ra } a_{\text {NEFA }} & \text { Rate of appearance of NEFA } \\ \text { SFA } & \text { Saturated fatty acid } \\ \text { TAG } & \text { Triacylglycerol } \\ \text { TTR } & \text { Tracer:tracee ratio }\end{array}$

\section{Introduction}

Systemic lipid overflow, which is driven by adipose tissue dysfunction and impaired skeletal muscle lipid handling, is associated with insulin resistance (IR) [1]. Increased circulating triacylglycerol (TAG) and NEFA concentrations are often found in IR because of impaired adipose tissue lipid handling 
[2-4]. This results in an increased lipid supply to other nonadipose tissues, such as liver and skeletal muscle. Due to an impaired capacity to oxidise fatty acids (FAs) [5, 6], these lipids may accumulate and interfere with insulin signalling in the liver and skeletal muscle [7, 8]. Over the last decade, it has become clear that the amount of lipids per se does not determine IR. Rather, a complex interplay between FA supply, FA type, muscle lipid turnover, subcellular localisation and composition of specific bioactive lipid metabolites seems to determine skeletal muscle IR $[1,8,9]$.

The contribution of dietary fat (chylomicron-TAG) and endogenous fat (NEFA and VLDL-TAG) to skeletal muscle FA handling is not well understood. Elevated plasma NEFA concentrations may result from both expanded fat mass [2] and reduced peripheral clearance $[5,10]$. Despite a reduced lipolysis per unit fat mass because of hyperinsulinaemia [11, 12], the total amount of NEFA released from adipose tissue in the postprandial state seems to be elevated in the obese insulin resistant state [13]. Furthermore, in situations with plasma insulin concentrations comparable to insulin levels achieved during a hyperinsulinaemic-euglycaemic clamp, the spillover from FAs derived from lipoprotein lipase (LPL)-mediated TAG hydrolysis in adipose tissue has been shown to be less suppressed in obese patients with type 2 diabetes than in nonobese healthy controls [14]. This increase in adipose tissue NEFA output might lead to increased hepatic VLDL-TAG production and elevated plasma TAG concentrations [15, 16]. Bickerton et al [17] demonstrated that dietary FAs were preferentially taken up in adipose tissue and skeletal muscle in the postprandial state in healthy lean humans, even though VLDL particles were abundantly present after the meal [11].

Up to now, most studies investigating combined VLDLand chylomicron-TAG metabolism have been performed in healthy, lean humans $[17,18]$. Bickerton et al [11] have shown elevated postprandial plasma VLDL- and chylomicron-TAG concentrations in overweight men with IR [11]. Moreover, we have recently demonstrated that an increased postprandial VLDL-TAG extraction was associated with IR in men with the metabolic syndrome [19]. However, studies involving the combined assessment of human skeletal muscle VLDL- and chylomicron-TAG metabolism, and intramuscular lipid species are limited. In addition, previous studies have used a relatively small sample size due to methodological difficulties as well as the high costs associated with these measurements. Therefore, extensive human in vivo data on skeletal muscle FA handling in IR are currently lacking. The aim of this study was to investigate fasting and postprandial skeletal muscle FA handling in a large study cohort of overweight or obese participants with a wide range of IR. A dual stable isotope tracer technique using labelled palmitate in combination with measurements of differences in arteriovenous concentrations across forearm muscle and forearm blood flow was used in this study, as previously validated [17]. This enabled us to differentiate between the metabolic fate of dietary and endogenous FA. In addition, skeletal muscle biopsies were taken to investigate skeletal muscle lipid metabolites, their fractional synthetic rates (FSRs) and the transcriptional regulation of FA metabolism.

\section{Methods}

Study participants Seventy-four participants (62 men and 12 women) with the metabolic syndrome or impaired glucose metabolism were obtained from the Maastricht biobank. These participants (described elsewhere in more detail [19-21]) underwent a high-saturated FA (SFA) mixed-meal test. Participants were divided into two groups based on the median of HOMA-IR (3.35); participants below the median of HOMA-IR formed the 'mild-IR' group $(n=37)$ and participants above the median formed the 'high-IR' group $(n=37)$. The local Medical Ethical Committee of Maastricht University Medical Center ${ }^{+}$approved the study protocols. All participants gave their written informed consent before participation.

High-fat mixed-meal test Participants were studied after an overnight fast and were asked to refrain from strenuous exercise and drinking alcohol for $24 \mathrm{~h}$ before the study day. In addition, they were asked to avoid food products naturally enriched with ${ }^{13} \mathrm{C}$ for 7 days before the study day. Forearm muscle metabolism was studied using arteriovenous concentration differences combined with measurements of forearm blood flow. Three catheters were inserted before the start of the experiment. One catheter was placed retrogradely into a superficial dorsal vein of a hand heated in a hot-box $\left(60^{\circ} \mathrm{C}\right)$ to obtain an arterialised blood sample. In the same arm another catheter was placed in an antecubital vein for the infusion of the $\left[{ }^{2} \mathrm{H}_{2}\right]$ palmitate tracer. A third catheter was placed retrogradely in a deep antecubital vein of the contralateral forearm to sample venous blood draining the forearm muscle. After taking an arterialised and deep-venous background sample at $90 \mathrm{~min}$ before meal ingestion, a continuous i.v. infusion of the stable isotope tracer, $\left[{ }^{2} \mathrm{H}_{2}\right]$ palmitate (97\% enrichment; Cambridge Isotope Laboratories, Andover, MA, USA) complexed to albumin was started $\left(0.035 \mu \mathrm{mol}[\mathrm{kg} \text { body weight }]^{-1} \mathrm{~min}^{-1}\right)$. Baseline blood sampling was started after $1 \mathrm{~h}$ of tracer infusion to allow for isotopic equilibration to occur. Blood samples were taken simultaneously from the dorsal hand vein and the deep muscle vein at three time points during fasting. Samples were also taken at six time points postprandially after consumption of a high-SFA mixed-meal (at ' 0 min') containing $200 \mathrm{mg}$ [U- ${ }^{13} \mathrm{C}$ ]palmitate $(98 \%$ enrichment; Cambridge Isotope Laboratories). The liquid meal provided 2.6 MJ energy, consisting of 61 energy \% (E\%) fat $(35.5 \mathrm{E} \%$, SFA; $18.8 \mathrm{E} \%$, monounsaturated FA [MUFA]; $1.7 \mathrm{E} \%$ polyunsaturated FA 
[PUFA]), $33 \mathrm{E} \%$ carbohydrates and $6.3 \mathrm{E} \%$ protein. Analysis of forearm blood flow before blood sampling and details of other biochemical analyses have been described previously [19].

Skeletal muscle biopsies Skeletal muscle biopsies were obtained from the vastus lateralis muscle after local anaesthesia of the skin and fascia using the Bergström method with suction [22]. Muscle biopsies were taken during fasting and at the end of the postprandial period (240 min). Muscle biopsies were lyophilised and dissected free of extramyocellular lipid, blood and connective tissue under a microscope. Details of lipid extraction and quantification have been described previously [19]. Skeletal muscle expression of genes related to transcription factors, oxidative metabolism, lipid synthesis and lipolysis were analysed. Gene expression was normalised relative to the geometric mean of the internal reference genes ( $\beta$-actin, $\beta$-2-microglobulin and/ or ribosomal protein L13a). Details of accession numbers, RNA primer sequences and RT-PCR analysis of these genes have been described previously $[19,20]$. Since limited muscle biopsy samples were available, not all genes have been measured in all individuals.

Calculations Net fluxes of metabolites (labelled and unlabelled) across the forearm were calculated by multiplying the arteriovenous concentration difference by forearm plasma flow. Plasma flow was measured using plethysmography and calculated by multiplying forearm blood flow with ([1-haematocrit (\%vol.)]/100). A positive flux indicates net uptake across forearm muscle, whereas a negative flux indicates net release. Labelled NEFA and TAG concentrations were calculated as the product of tracer:tracee ratio (TTR) of $\left[{ }^{2} \mathrm{H}_{2}\right]$ palmitate and $\left[\mathrm{U}_{-}^{13} \mathrm{C}\right]$ palmitate and the concentration of palmitate in NEFA and TAG, as reported previously [19].

The degree of saturation of skeletal muscle TAG, diacylglycerol (DAG), phospholipid (PL) and NEFA (\%) was calculated by dividing the sum of unsaturated FAs by the total amount of FAs in a fraction multiplied by 100 . The FSR of skeletal muscle NEFA, TAG, DAG and PL was calculated using skeletal muscle NEFA as the precursor pool for lipid synthesis. The increase in TTR of $\left[\mathrm{U}-{ }^{13} \mathrm{C}\right]$ from fasting to $4 \mathrm{~h}$ postprandial measures was divided by the enrichment of skeletal muscle NEFA and expressed as per cent per hour $(\% / \mathrm{h})$. Postprandial areas under the curve $\left(\mathrm{AUC}_{0-4 \mathrm{~h}}\right)$ of metabolites were calculated using the trapezium rule and in this study data are presented as $\mathrm{AUC}_{0-4 \mathrm{~h}} / \mathrm{min}$.

Statistics In this study all data are expressed as mean \pm SEM. Participant characteristics and differences in skeletal muscle lipid handling during fasting and postprandial conditions of the mild-IR and high-IR group were compared using independent samples $t$ tests. A linear regression was performed with HOMA-IR and BMI and sex as co-variates. Variables were $\log _{\mathrm{e}}$-transformed if the assumption of normality was not met. The data were analysed using SPSS for Mac version 22.0 (SPSS, Chicago, IL, USA) and statistical significance was set at $p<0.05$.

\section{Results}

Study population Participant characteristics are summarised in Table 1. Age, waist:hip ratio and blood pressure were comparable between groups, while BMI was significantly higher in the high-IR group $(p=0.002)$. By design, mean HOMA-IR was different between the two groups (mild-IR vs high-IR: $2.5 \pm 0.1$ vs $4.7 \pm 0.3$, respectively, $p<0.001$ ).

Arterialised metabolites, forearm muscle metabolism and forearm blood flow Fasting arterialised plasma glucose (Fig. 1a) and insulin (Fig. 1b) concentrations were significantly higher in the high-IR group than in the mild-IR group ( $p=0.002$ and $p<0.001$, respectively) and remained higher throughout the postprandial period $(p=0.035$ and $p<0.001$, respectively). Net glucose uptake across forearm muscle was similar in the high-IR and mild-IR groups under fasting conditions, but was significantly lower in the high-IR group than in the mild-IR group after meal ingestion $\left(\mathrm{AUC}_{0-4 \mathrm{~h}}\right.$ $0.59 \pm 0.04$ vs $0.76 \pm 0.07 \mu \mathrm{mol}[100 \mathrm{ml} \text { tissue }]^{-1} \mathrm{~min}^{-1}$, respectively, $p=0.034$ ), indicating a lower postprandial insulin sensitivity in the high-IR group (see Table 2 and Fig. 1c). Arterialised fasting plasma glycerol concentrations $(p=0.006)$ and lactate concentrations were significantly higher $(p=0.006)$ in the high-IR group than in the mild-IR group (Table 2). Forearm blood flow and glycerol release were similar between the two IR groups, both during fasting and postprandial conditions. Moreover, fasting $(p=0.002)$ and postprandial $(p=0.048)$ lactate release was positively associated with IR (Table 2).

Whole-body and forearm muscle NEFA metabolism Fasting arterialised NEFA concentrations were similar in the high-IR and mild-IR groups (Fig. 2a). After the high-SFA meal ingestion, arterialised NEFA concentrations decreased to the same extent in both groups and returned to nearbaseline values at the end of the postprandial period, with no significant differences observed between the groups. $\left[{ }^{2} \mathrm{H}_{2}\right]$ palmitate was infused i.v. and was mixed with the plasma NEFA pool. The TTR reached steady state during fasting measurements (Fig. 2c, d). Consistent with these findings, the rate of appearance of NEFA $\left(\mathrm{Ra}_{\mathrm{NEFA}}\right)$ decreased after the meal (Fig. 2b), which is an indication of suppression of whole-body lipolysis. A reduction in postprandial suppression of the $R a_{\text {NEFA }}$ was observed in the high-IR group compared with the mild-IR group, although the difference did not reach statistical significance ( $p=0.079$, Fig. $2 b)$. There were no 
Table 1 Characteristics of participants

\begin{tabular}{llllll}
\hline Characteristic & $\begin{array}{l}\text { Mild-IR } \\
(n=37)\end{array}$ & $\begin{array}{l}\text { High-IR } \\
(n=37)\end{array}$ & $\begin{array}{l}\text { Total group } \\
(n=74)\end{array}$ & $\begin{array}{l}\text { Range } \\
(n=74)\end{array}$ & $p$ value $^{\mathrm{a}}$ \\
\hline Male $(n) /$ Female $(n)$ & $33 / 4$ & $29 / 8$ & $62 / 12$ & & \\
Age (years) & $58.0 \pm 1.4$ & $59.0 \pm 1.1$ & $58.5 \pm 0.9$ & $36-70$ & 0.582 \\
Body weight $(\mathrm{kg})$ & $89.8 \pm 1.9$ & $95.1 \pm 2.1$ & $92.5 \pm 1.4$ & $64.0-115.0$ & 0.064 \\
BMI $\left(\mathrm{kg} / \mathrm{m}^{2}\right)$ & $29.2 \pm 0.5$ & $31.7 \pm 0.6$ & $30.5 \pm 0.4$ & $22.7-39.5$ & 0.002 \\
Waist:hip ratio & $1.02 \pm 0.01$ & $1.03 \pm 0.01$ & $1.02 \pm 0.01$ & $0.89-1.17$ & 0.494 \\
Systolic blood pressure $(\mathrm{mmHg})$ & $135 \pm 2$ & $136 \pm 2$ & $135 \pm 2$ & $105-174$ & 0.636 \\
Diastolic blood pressure $(\mathrm{mmHg})$ & $84 \pm 2$ & $85 \pm 1$ & $85 \pm 1$ & $68-110$ & 0.944 \\
Fasting plasma glucose $(\mathrm{mmol} / \mathrm{l})$ & $5.4 \pm 0.1$ & $5.7 \pm 0.1$ & $5.5 \pm 0.1$ & $4.6-6.7$ & 0.002 \\
Fasting plasma insulin $(\mathrm{pmol} / \mathrm{l})$ & $72.3 \pm 2.4$ & $130.2 \pm 6.6$ & $101.2 \pm 4.9$ & $50-263.3$ & $<0.001$ \\
Fasting plasma NEFA $(\mu \mathrm{mol} / \mathrm{l})$ & $561 \pm 22$ & $598 \pm 26$ & $580 \pm 17$ & $296-1002$ & 0.287 \\
Fasting plasma TAG $(\mu \mathrm{mol} / \mathrm{l})$ & $1320 \pm 103$ & $1246 \pm 85$ & $1283 \pm 66$ & $415-3232$ & 0.582 \\
HOMA-IR & $2.5 \pm 0.1$ & $4.7 \pm 0.3$ & $3.6 \pm 0.2$ & $1.68-11.3$ & $<0.001$ \\
\hline
\end{tabular}

Values are presented as mean \pm SEM

${ }^{a} p$ value for difference between mild-IR and high-IR group, Student's $t$ test for unpaired samples differences in arterialised concentrations of $\left[{ }^{2} \mathrm{H}_{2}\right]$ palmitate and $\left[\mathrm{U}_{-}{ }^{13} \mathrm{C}\right]$ palmitate in NEFA between groups (data not shown).

The TTR of $\left[{ }^{2} \mathrm{H}_{2}\right]$ palmitate in NEFA was higher in arterialised vs deep-venous plasma at all time points in both groups. This reflects dilution of the $\left[{ }^{2} \mathrm{H}_{2}\right]$ tracer in the plasma NEFA pool across forearm muscle. The TTR of $\left[\mathrm{U}-{ }^{13} \mathrm{C}\right]$ palmitate in NEFA (resulting from spillover of FA
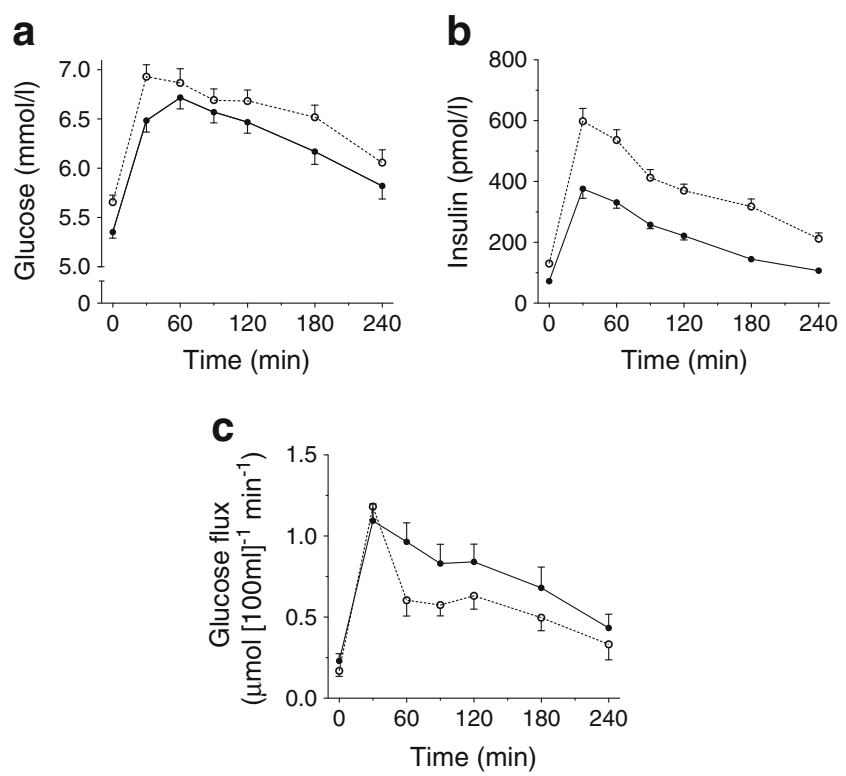

Fig. 1 Arterialised plasma glucose (a) and insulin (b) concentrations and glucose flux (c) during fasting ( $0 \mathrm{~min})$ and after consumption of a highSFA meal. Black circles, mild-IR group; white circles, high-IR group. Student's $t$ test for unpaired samples showed significant effect of group on fasting and postprandial plasma glucose $\left(p=0.002\right.$ and $\mathrm{AUC}_{0-4 \mathrm{~h}}$ : $p=0.035$, respectively), fasting and postprandial plasma insulin $\left(p<0.001\right.$ and $\mathrm{AUC}_{0-4 \mathrm{~h}}: p<0.001$, respectively) and postprandial glucose flux $\left(\mathrm{AUC}_{0-4 \mathrm{~h}}: p=0.034\right)$. Values are presented as mean $\pm \mathrm{SEM}$ derived from chylomicron-TAG hydrolysis) was not different in arterialised vs deep-venous plasma at all time points in both groups (Fig. 2c, d).

Fasting and postprandial net extraction of plasma NEFA across forearm muscle did not differ between groups. Furthermore, there was consistent uptake of $\left[{ }^{2} \mathrm{H}_{2}\right]$ palmitate across forearm muscle during the study period and this was similar in both groups (Table 2).

Whole-body and forearm muscle TAG metabolism Comparable arterialised TAG concentrations between the high-IR and mild-IR groups were observed during fasting and postprandial conditions (Fig. 3a). The $\left[{ }^{2} \mathrm{H}_{2}\right]$ palmitate tracer was measurable in plasma TAG from the first baseline sample onwards, reflecting incorporation of the i.v. infused tracer into VLDL-TAG (Fig. 3b). The $\left[\mathrm{U}_{-}{ }^{13} \mathrm{C}\right]$ palmitate tracer, which was given with the meal, appeared in plasma TAG from 60 min after meal ingestion, representing chylomicron-TAG in the circulation (Fig. 3b). During the postprandial period both labelled TAG fractions increased without significant differences between groups.

Fasting net extraction of $\left[{ }^{2} \mathrm{H}_{2}\right]$ palmitate TAG across forearm muscle was higher in the high-IR group than in the mildIR group, although the difference did not reach statistical significance $(p=0.069)$. Postprandial net extraction of $\left[{ }^{2} \mathrm{H}_{2}\right]$ palmitate TAG was significantly elevated in the highIR group vs the mild-IR group ( $p=0.045)$ (Fig. 3c). In line with this, we found a significant linear association between postprandial net extraction of $\left[{ }^{2} \mathrm{H}_{2}\right]$ palmitate TAG and HOMA-IR, even after adjustment for BMI and sex (standardised $\beta=0.294 ; p=0.037$; Table 2). The net extraction of $\left[\mathrm{U}_{-}{ }^{13} \mathrm{C}\right]$ palmitate TAG across forearm muscle could be detected from 60 min onwards and did not differ significantly between groups (Table 2, Fig. 3d). 
Table 2 Fasting and postprandial lipid metabolism

\begin{tabular}{|c|c|c|c|c|c|}
\hline Variable & Mild-IR & High-IR & $p$ value $^{\mathrm{a}}$ & Total group SE $\beta$ & $p$ value $\mathrm{e}^{\mathrm{b}}$ \\
\hline \multicolumn{6}{|c|}{ Forearm blood flow ( $\left.\mathrm{ml}[100 \mathrm{ml} \text { tissue }]^{-1} \min ^{-1}\right)$} \\
\hline Fasting & $2.5 \pm 0.2$ & $2.5 \pm 0.2$ & 0.896 & 0.054 & 0.682 \\
\hline Postprandial & $2.6 \pm 0.2$ & $2.8 \pm 0.2$ & 0.476 & 0.118 & 0.369 \\
\hline \multicolumn{6}{|l|}{ Glycerol $(\mu \mathrm{mol} / \mathrm{l})$} \\
\hline Fasting & $84.6 \pm 3.9$ & $118.5 \pm 11.1$ & 0.006 & 0.200 & 0.090 \\
\hline Postprandial & $64.9 \pm 3.6$ & $92.9 \pm 10.6$ & 0.016 & 0.278 & 0.025 \\
\hline \multicolumn{6}{|l|}{ Lactate $(\mu \mathrm{mol} / \mathrm{l})$} \\
\hline Fasting & $0.62 \pm 0.04$ & $0.79 \pm 0.05$ & 0.006 & 0.438 & $<0.001$ \\
\hline Postprandial & $0.98 \pm 0.05$ & $1.10 \pm 0.05$ & 0.081 & 0.224 & 0.087 \\
\hline \multicolumn{6}{|c|}{ Net flux across forearm muscle } \\
\hline \multicolumn{6}{|c|}{ Glucose $\left(\mu \mathrm{mol}[100 \mathrm{ml} \text { tissue }]^{-1} \min ^{-1}\right)$} \\
\hline Fasting & $0.23 \pm 0.05$ & $0.17 \pm 0.03$ & 0.274 & -0.083 & 0.524 \\
\hline Postprandial & $0.76 \pm 0.07$ & $0.59 \pm 0.04$ & 0.034 & -0.147 & 0.226 \\
\hline \multicolumn{6}{|c|}{ Glycerol (nmol [100 ml tissue $]^{-1} \min ^{-1}$ ) } \\
\hline Fasting & $-28.3 \pm 5.5$ & $-27.0 \pm 7.7$ & 0.883 & 0.224 & 0.092 \\
\hline Postprandial & $-20.4 \pm 4.5$ & $-25.2 \pm 6.5$ & 0.541 & 0.081 & 0.543 \\
\hline \multicolumn{6}{|c|}{ Lactate (nmol [100 ml tissue $]^{-1} \min ^{-1}$ ) } \\
\hline Fasting & $-0.18 \pm 0.02$ & $-0.12 \pm 0.03$ & 0.123 & 0.384 & 0.002 \\
\hline Postprandial & $0.01 \pm 0.02$ & $0.04 \pm 0.03$ & 0.472 & 0.249 & 0.048 \\
\hline \multicolumn{6}{|c|}{ NEFA (nmol [100 ml tissue $]^{-1} \min ^{-1}$ ) } \\
\hline Fasting & $-6.9 \pm 20.4$ & $26.6 \pm 24.6$ & 0.300 & 0.165 & 0.210 \\
\hline Postprandial & $-0.8 \pm 9.5$ & $8.7 \pm 13.4$ & 0.565 & 0.112 & 0.405 \\
\hline \multicolumn{6}{|c|}{$\left[{ }^{2} \mathrm{H}_{2}\right]$ palmitate NEFA (nmol [100 ml tissue $]^{-1} \mathrm{~min}^{-1}$ ) } \\
\hline Fasting & $1.69 \pm 0.12$ & $1.58 \pm 0.14$ & 0.539 & 0.017 & 0.902 \\
\hline Postprandial & $1.50 \pm 0.09$ & $1.53 \pm 0.14$ & 0.846 & 0.171 & 0.208 \\
\hline \multicolumn{6}{|c|}{ TAG (nmol [100 ml tissue $]^{-1} \min ^{-1}$ ) } \\
\hline Fasting & $10.2 \pm 13.2$ & $45.5 \pm 12.1$ & 0.052 & 0.094 & 0.466 \\
\hline Postprandial & $53.9 \pm 17.2$ & $51.9 \pm 28.4$ & 0.954 & -0.105 & 0.422 \\
\hline \multicolumn{6}{|c|}{$\left[{ }^{2} \mathrm{H}_{2}\right]$ palmitate TAG (nmol [100 ml tissue $]^{-1} \min ^{-1}$ ) } \\
\hline Fasting & $-0.24 \pm 0.16$ & $0.56 \pm 0.41$ & 0.069 & 0.241 & 0.076 \\
\hline Postprandial & $-0.43 \pm 0.38$ & $0.57 \pm 0.32$ & 0.045 & 0.294 & 0.037 \\
\hline \multicolumn{6}{|c|}{$\left[\mathrm{U}-{ }^{13} \mathrm{C}\right]$ palmitate TAG (nmol $[100 \mathrm{ml} \text { tissue }]^{-1} \mathrm{~min}^{-1}$ ) } \\
\hline \multicolumn{6}{|l|}{ Fasting $^{\mathrm{c}}$} \\
\hline Postprandial & $0.86 \pm 0.16$ & $0.66 \pm 0.16$ & 0.353 & -0.046 & 0.736 \\
\hline
\end{tabular}

Values are presented as mean \pm SEM

Postprandial values are calculated from $\mathrm{AUC}_{0-4 \mathrm{~h}}$

A positive flux indicates net uptake across forearm muscle, whereas a negative flux indicates net release

${ }^{a} p$ value for difference between mild-IR and high-IR group, Student's $t$ test for unpaired samples

${ }^{\mathrm{b}} p$ value for multiple linear regression

${ }^{\mathrm{c}}\left[\mathrm{U}_{-}{ }^{13} \mathrm{C}\right]$ palmitate was given with the high-SFA meal, hence fasting data are not available.

$\left[{ }^{2} \mathrm{H}_{2}\right]$ palmitate TAG fasting, $n=34 ;\left[{ }^{2} \mathrm{H}_{2}\right]$ palmitate NEFA postprandial and [U- $\left.{ }^{13} \mathrm{C}\right]$ palmitate TAG postprandial, $n=33$; $\left[{ }^{2} \mathrm{H}_{2}\right]$ palmitate TAG postprandial (mild-IR), $n=29 ;\left[{ }^{2} \mathrm{H}_{2}\right]$ palmitate TAG postprandial (high-IR), $n=32$

SE $\beta$, standardised $\beta$ coefficient for HOMA-IR, adjusted for sex and BMI
Intramuscular lipid metabolism Skeletal muscle TAG, DAG and NEFA content were comparable between high-IR and mild-IR groups (Table 3 ). The PL content was lower in the high-IR group than in the mild-IR group, although the difference did not reach statistical significance $(60.5 \pm 3.2$ vs $70.2 \pm 3.6 \mu \mathrm{mol} /[\mathrm{g}$ dry weight $]$, respectively, $p=0.055$ ). However, there was no significant linear association between PL and measures of IR (Table 3). Intramuscular lipid 

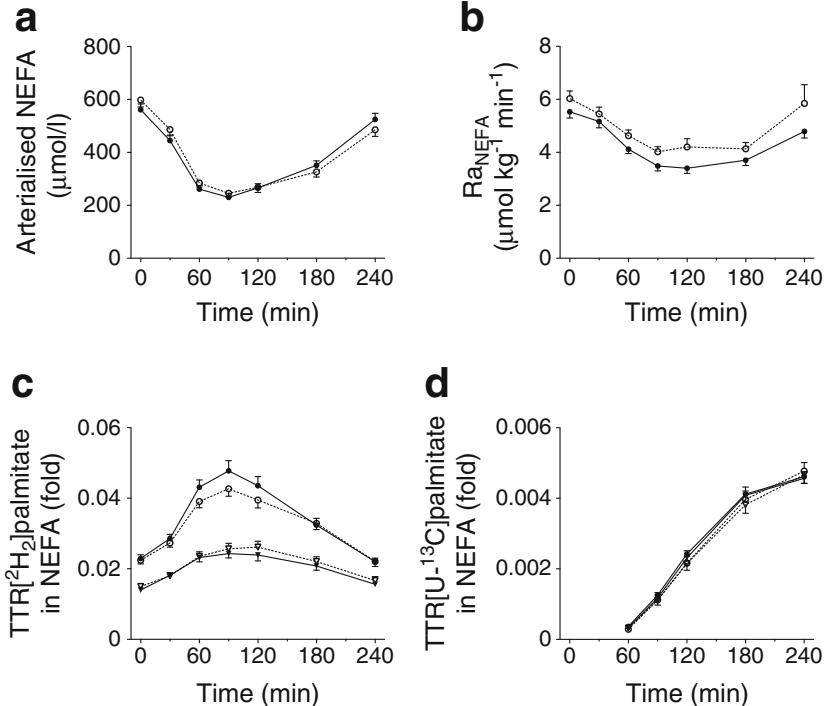

Fig. 2 Postprandial whole-body NEFA metabolism. Arterialised plasma NEFA concentrations (a), $\mathrm{Ra}_{\mathrm{NEFA}}(\mathbf{b})$, and the TTR of $\left[{ }^{2} \mathrm{H}_{2}\right]$ palmitate (c) and $\left[\mathrm{U}_{-}{ }^{13} \mathrm{C}\right]$ palmitate $(\mathbf{d})$ in the plasma NEFA fraction during fasting ( $0 \mathrm{~min}$ ) and after consumption of a high-SFA meal. Black symbols, mild-IR group; white symbols, high-IR group; in (c) and (d) circles, arterialised plasma concentrations and triangles, forearm venous plasma concentrations. Values are presented as mean \pm SEM
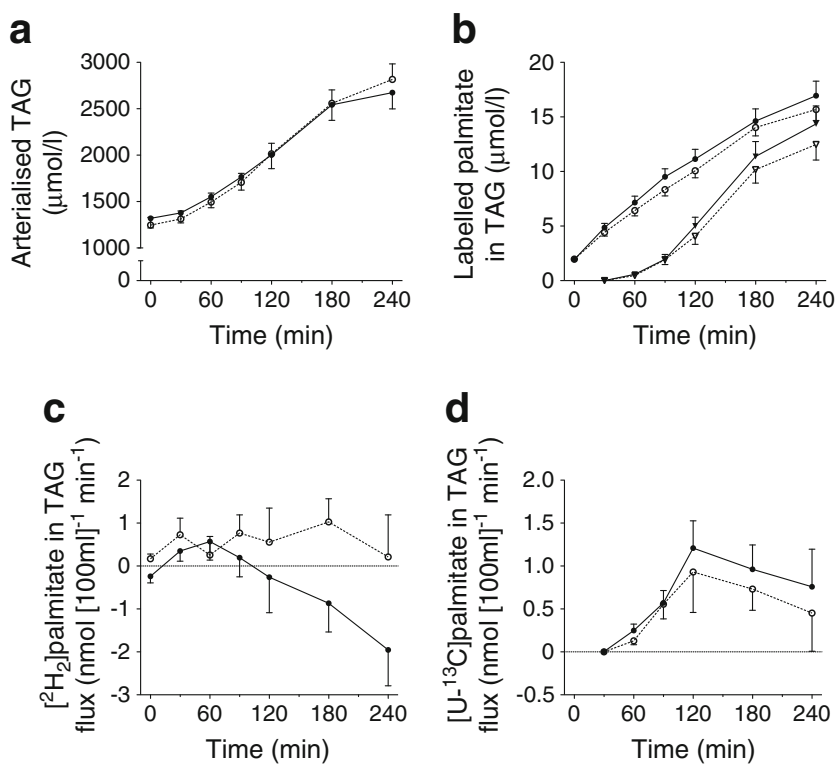

Fig. 3 Postprandial whole-body and forearm muscle TAG metabolism. Arterialised plasma TAG concentrations (a), $\left[{ }^{2} \mathrm{H}_{2}\right]$ - and $\left[\mathrm{U}-{ }^{13} \mathrm{C}\right]$ palmitate concentrations in the plasma TAG fraction (b), and the net flux of $\left[{ }^{2} \mathrm{H}_{2}\right]$ palmitate TAG (c) and $\left[\mathrm{U}_{-}{ }^{13} \mathrm{C}\right]$ palmitate TAG (d) across forearm muscle during fasting ( $0 \mathrm{~min}$ ) and after consumption of a high-SFA meal. A positive flux indicates net uptake across forearm muscle, whereas a negative flux indicates net release. Black symbols, mild-IR group; white symbols, high-IR group; in (b) circles, $\left[{ }^{2} \mathrm{H}_{2}\right]$ palmitate TAG and triangles, $\left[\mathrm{U}-{ }^{13} \mathrm{C}\right]$ palmitate TAG. Student's $t$ test for unpaired samples showed a significant effect of group on postprandial net flux of $\left[{ }^{2} \mathrm{H}_{2}\right]$ palmitate TAG $\left(\mathrm{AUC}_{0-4 \mathrm{~h}} ; p=0.045\right)$. Values are presented as mean $\pm \mathrm{SEM}$ composition was different between groups, with a significantly higher degree of saturation in the muscle NEFA pool in participants with high-IR compared with those with mild-IR $(51.8 \pm 2.8 \%$ vs $43.9 \pm 2.5 \%$, respectively, $p=0.039)$, but there was no significant linear association with IR (Table 3). This difference was mainly explained by higher percentages of myristic acid (C14:0; $3.5 \pm 0.7 \%$ vs $2.1 \pm 0.4 \%, p=0.078)$, pentadecyclic acid (C15:0; $4.5 \pm 1.5 \%$ vs $1.2 \pm 0.3 \%$, $p=0.038)$ and tricosylic acid (C23:0; $3.0 \pm 1.1 \%$ vs 0.8 $\pm 0.4 \%, p=0.064)$ in the high-IR group vs mild-IR group (Fig. 4a). Furthermore, the percentage of PUFA in the NEFA pool was lower in the high-IR group than in the mild-IR group $(13.0 \pm 1.1 \%$ vs $17.0 \pm 1.4 \%, p=0.034$; Table 3$)$. In addition, lipid composition in the intramuscular DAG pool differed between high-IR and mild-IR groups (Table 3): in the highIR group, the percentage PUFA was significantly lower $(p=0.022)$. Linear regression showed a non-significant negative association between the percentage of PUFA in the DAG pool and HOMA-IR. Furthermore, a higher percentage of MUFA was observed in the DAG pool of the high-IR group compared with the mild-IR group ( $p=0.052$; Table 3$)$. Although the total saturation of the lipid content in the DAG pool did not differ between groups (Table 3), the percentage of palmitate (C16:0) in the DAG pool of the high-IR group was significantly higher compared with that in the mild-IR group (22.1 $\pm 0.7 \%$ vs $24.6 \pm 0.8 \%$, respectively, $p=0.024$; Fig. $4 \mathrm{~b}$ ).

The FSR of skeletal muscle TAG, DAG and PL was comparable between groups (Table 3), indicating that a similar proportion of palmitate from the intramuscular NEFA pool was directed towards storage after the high-SFA meal.

Fasting skeletal muscle mRNA expression of genes encoding proteins involved in oxidative metabolism, lipid synthesis and lipolysis is shown in Table 4. Skeletal muscle gene expression of GPAT1 (also known as GPAM), a gene involved in lipid synthesis, was significantly lower $(p=0.050)$ in the high-IR group than in the mild-IR group, even when adjusted for sex and BMI using linear regression analysis (standardised $\beta=-0.666 ; p=0.002$ ). Furthermore, the expression level of NDUFB5, encoding a subunit of complex I in the electron transport chain, tended to be lower in the high-IR vs the mild-IR group ( $p=0.062)$, whilst the expression of the intracellular lipase gene $A T G L$ (also known as PNPLA2) tended to be higher in the high-IR group $(p=0.052)$.

\section{Discussion}

The present study demonstrated that postprandial forearm muscle VLDL-TAG extraction was elevated in individuals with high-IR compared with mild-IR. This elevation in VLDL-TAG extraction was accompanied by increased saturation of the intramuscular NEFA pool. Both effects were independent of BMI. These data support the notion of an 
Table 3 Skeletal muscle lipid content and composition during fasting and the FSR of the muscle lipid pools after a high-SFA meal

\begin{tabular}{|c|c|c|c|c|c|}
\hline Lipid & $\begin{array}{l}\text { Mild-IR } \\
(n=35)\end{array}$ & $\begin{array}{l}\text { High-IR } \\
(n=28)\end{array}$ & $p$ value $^{\mathrm{a}}$ & Total group SE $\beta$ & $p$ value $^{\mathrm{b}}$ \\
\hline \multicolumn{6}{|l|}{ NEFA } \\
\hline Total $(\mu \mathrm{mol} /[\mathrm{g}$ dry weight $])$ & $5.9 \pm 0.8$ & $4.9 \pm 0.8$ & 0.360 & -0.058 & 0.642 \\
\hline$\%$ SFA & $43.9 \pm 2.5$ & $51.8 \pm 2.8$ & 0.039 & 0.219 & 0.112 \\
\hline$\%$ MUFA & $39.1 \pm 1.9$ & $35.2 \pm 2.3$ & 0.183 & -0.183 & 0.162 \\
\hline$\%$ PUFA & $17.0 \pm 1.4$ & $13.0 \pm 1.1$ & 0.034 & -0.162 & 0.266 \\
\hline FSR $(\% / h)$ & $0.38 \pm 0.05$ & $0.36 \pm 0.07$ & 0.747 & -0.069 & 0.619 \\
\hline \multicolumn{6}{|l|}{ DAG } \\
\hline Total ( $\mu \mathrm{mol} /[\mathrm{g}$ dry weight $])$ & $10.8 \pm 2.8$ & $6.2 \pm 0.7$ & 0.151 & -0.195 & 0.160 \\
\hline$\%$ SFA & $37.8 \pm 1.9$ & $36.6 \pm 0.8$ & 0.594 & -0.093 & 0.535 \\
\hline$\%$ MUFA & $44.2 \pm 1.6$ & $47.6 \pm 0.6$ & 0.052 & 0.255 & 0.086 \\
\hline$\%$ PUFA & $18.0 \pm 0.8$ & $15.7 \pm 0.5$ & 0.022 & -0.271 & 0.059 \\
\hline $\operatorname{FSR}(\% / \mathrm{h})$ & $0.33 \pm 0.05$ & $0.29 \pm 0.05$ & 0.538 & -0.058 & 0.692 \\
\hline \multicolumn{6}{|l|}{ TAG } \\
\hline Total ( $\mu \mathrm{mol} /[\mathrm{g}$ dry weight $])$ & $182.6 \pm 24.3$ & $232.1 \pm 42.5$ & 0.301 & 0.126 & 0.365 \\
\hline$\%$ SFA & $36.7 \pm 0.9$ & $35.8 \pm 0.9$ & 0.477 & -0.157 & 0.273 \\
\hline$\%$ MUFA & $47.9 \pm 1.0$ & $50.1 \pm 0.7$ & 0.076 & 0.046 & 0.749 \\
\hline$\%$ PUFA & $15.3 \pm 0.8$ & $14.1 \pm 1.0$ & 0.325 & 0.112 & 0.444 \\
\hline FSR $(\% / h)$ & $0.28 \pm 0.05$ & $0.21 \pm 0.04$ & 0.325 & -0.186 & 0.209 \\
\hline \multicolumn{6}{|l|}{ PL } \\
\hline Total ( $\mu \mathrm{mol} /[\mathrm{g}$ dry weight $])$ & $70.2 \pm 3.6$ & $60.5 \pm 3.2$ & 0.055 & -0.155 & 0.260 \\
\hline$\%$ SFA & $41.3 \pm 0.8$ & $40.4 \pm 0.6$ & 0.364 & -0.046 & 0.754 \\
\hline$\%$ MUFA & $11.3 \pm 0.3$ & $11.4 \pm 0.5$ & 0.903 & 0.017 & 0.909 \\
\hline$\%$ PUFA & $47.4 \pm 1.0$ & $48.2 \pm 0.7$ & 0.496 & 0.030 & 0.838 \\
\hline $\operatorname{FSR}(\% / \mathrm{h})$ & $0.10 \pm 0.01$ & $0.09 \pm 0.01$ & 0.486 & -0.006 & 0.966 \\
\hline
\end{tabular}

Values are presented as mean \pm SEM

${ }^{a} p$ value for difference between mild-IR and high-IR group, Student's $t$ test for unpaired samples

${ }^{\mathrm{b}} p$ value for multiple linear regression

SE $\beta$, standardised $\beta$ coefficient for HOMA-IR, adjusted for sex and BMI important role for disturbances in skeletal muscle FA handling in the progression of whole-body IR.

Disturbances in skeletal muscle FA handling have been implicated in the aetiology of IR and type 2 diabetes [1, 23]. Our group has recently demonstrated that higher postprandial plasma TAG concentrations and increased net TAG extraction across forearm muscle were accompanied by decreased postprandial insulin sensitivity in participants with impaired glucose metabolism compared with normal glucose tolerance [24]. Furthermore, we showed a higher postprandial VLDL-TAG extraction by skeletal muscle in men with IR compared with controls with the metabolic syndrome, matched for age and BMI, despite a similar TAG supply [19]. More recently, we demonstrated that increased muscle VLDL-TAG extraction and reduced lipid turnover of SFA, rather than DAG content, accompany the more pronounced IR observed in humans with impaired glucose tolerance (IGT) compared with impaired fasting glucose (IFG) [20].

The present data extend our previous observations regarding FA handling by showing that postprandial forearm muscle
VLDL-TAG extraction was elevated in participants with highIR when compared with those with mild-IR. We included participants who encompassed the entire spectrum of insulin sensitivity, from insulin-sensitive to very-insulin-resistant states (HOMA-IR, 1.7-11.3) and with a wide range of adiposity (BMI, 22.7-39.5 kg/m²). This allowed us to differentiate between the effect of obesity and IR per se, and our present findings confirm those of previous studies that have suggested the existence of a relationship between impaired skeletal muscle FA handling and IR [1, 8, 25]. Moreover, our data imply that IR is primarily responsible for increased postprandial forearm muscle VLDL-TAG extraction, since we observed a significant linear association between VLDL-TAG extraction and IR. A potential mechanism for increased skeletal muscle VLDL-TAG extraction in participants with high-IR may involve differential apolipoprotein composition of the VLDL particles [16]. For example, higher plasma apoCII:apoCIII ratios have been shown in diabetic individuals, compared with a control group [26]. This variation in lipid composition might 
a

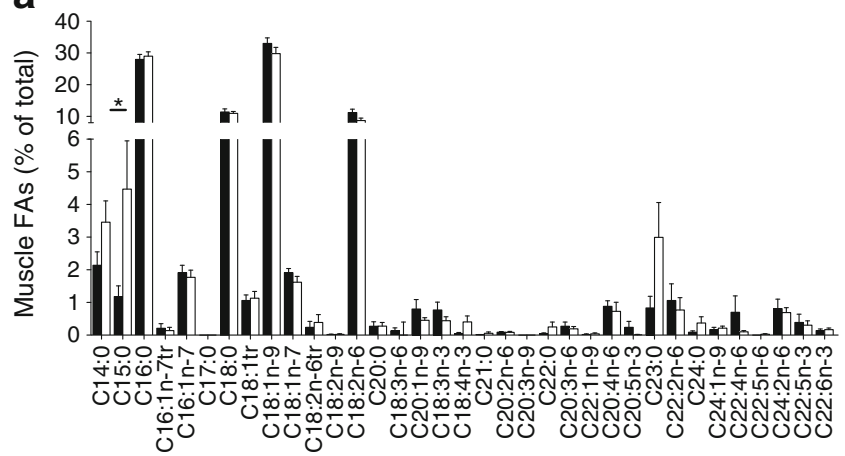

C

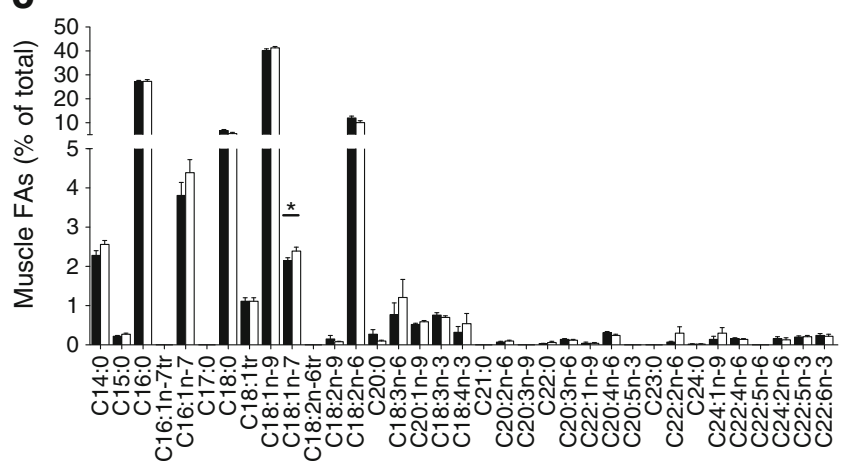

b

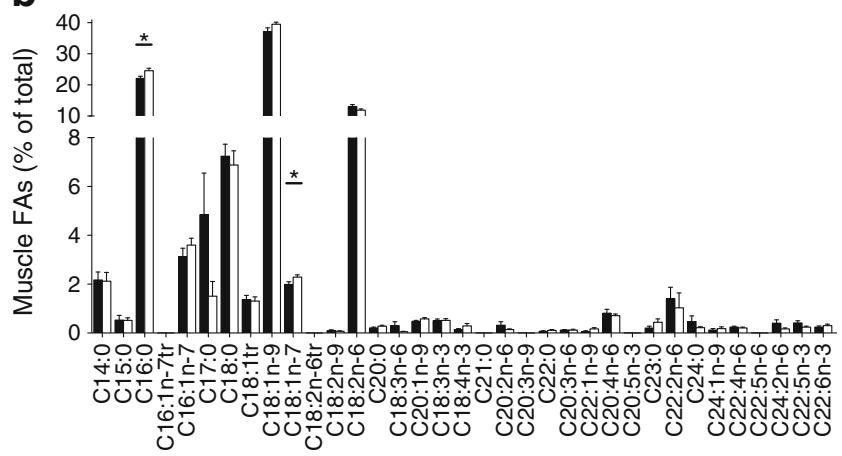

d

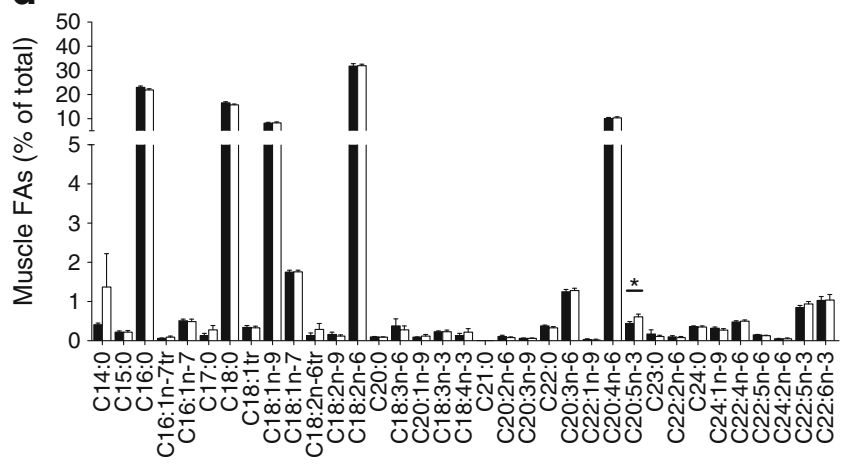

Fig. 4 Intramuscular NEFA (a), DAG (b), TAG (c) and PL (d) composition under fasting conditions. Black bars, mild-IR group; white bars, high-IR group. ${ }^{*} p<0.05$, mild-IR vs high-IR group, Student's $t$ test for unpaired samples. Values are presented as mean $\pm \mathrm{SEM}$

lead to higher a susceptibility for lipid degradation by in vivo skeletal muscle LPL [27]. Of note, we did not perform measurements in the late postprandial phase. It has been shown that dietary FAs appear in VLDL-TAG from $2-3 \mathrm{~h}$ after meal ingestion, making it difficult to separate chylomicron- and VLDL-TAG in the late postprandial phase using the current dual isotope approach [17, 28, 29]. Therefore, we cannot exclude the possibility that the increased TAG extraction observed in high-IR participants may also extend to chylomicron-TAG. In this context, an impaired inhibitory effect of insulin on skeletal muscle LPL action in the high-IR group [30], or impaired FA uptake via membrane-associated carrier proteins like CD36 [31] might possibly explain the observed differences.

In addition to an increased skeletal muscle lipid uptake, we observed differences in the intramyocellular FA partitioning between groups. Reduced re-esterification of NEFA into TAG may expose muscle to excess NEFA concentrations and bioactive lipid metabolites that may interfere with insulin signalling [23]. In line with this, a reduced incorporation of NEFA into TAG in primary myotubes from obese individuals with type 2 diabetes has previously been shown [32], indicating that the ability to incorporate FAs into TAG is an intrinsic feature of human muscle cells that is reduced in individuals with type 2 diabetes. Moreover, in vitro work has shown that muscle cells incubated with palmitate incorporated more FA towards the DAG pool, while the unsaturated FAs were diverted towards storage in the TAG pool [33]. In the present study, an increased percentage of palmitate in the DAG pool in the participants with high-IR was observed. Together with the reduced expression of GPAT1, which is involved in the first step in TAG synthesis in muscle, this might indicate a retention of SFA in the NEFA pool and may explain the lower percentage of PUFA in the DAG pool in the individuals with high-IR vs mild-IR. More recently, we reported a reduced FSR of palmitate into intramuscular TAG and DAG in individuals with combined IGT and IFG compared with participants with isolated IFG [20]. This has also been shown in obese humans with impaired glucose metabolism [34]. However, in the present study we did not observe significant differences between the mild-IR and high-IR groups in the FSR of palmitate into intramuscular TAG and DAG. Nevertheless, these findings suggest that the postprandial incorporation of FAs in TAG or DAG is not affected by the degree of IR per se.

Strikingly, in this study the increased saturation in the NEFA pool was mainly confined to specific SFAs, namely myristic acid (C14:0), pentadecyclic acid (C15:0) and tricosylic acid (C23:0). Recently, plasma odd-chain SFAs were shown to be inversely associated with type 2 diabetes and coronary heart disease incidence in large epidemiological studies [35]. Interestingly, dairy products are known to be the most important source for C15:0 [36]. This would certainly suggest a contribution of dietary fat to the increased saturation of the NEFA 
Table 4 Fasting skeletal muscle gene expression

\begin{tabular}{|c|c|c|c|c|c|}
\hline Gene & Mild-IR & High-IR & $p$ value $^{\mathrm{a}}$ & Total group SE $\beta$ & $p$ value $^{\mathrm{b}}$ \\
\hline Oxidative metabolism & $n=32$ & $n=30$ & & & \\
\hline$m C P T 1 B$ & $1.70 \pm 0.14$ & $1.74 \pm 0.13$ & 0.821 & 0.006 & 0.986 \\
\hline$P G C 1 \alpha(P P A R G C 1 A)$ & $0.51 \pm 0.05$ & $0.46 \pm 0.04$ & 0.428 & 0.027 & 0.847 \\
\hline$A C C 2$ & $1.52 \pm 0.14$ & $1.59 \pm 0.16$ & 0.741 & 0.020 & 0.891 \\
\hline$S D H B$ & $2.40 \pm 0.21$ & $1.97 \pm 0.22$ & 0.153 & -0.058 & 0.683 \\
\hline NDUFB5 & $2.67 \pm 0.17$ & $2.14 \pm 0.23$ & 0.062 & -0.243 & 0.076 \\
\hline Transcription factors & $n=28$ & $n=23$ & & & \\
\hline PPAR $\alpha(P P A R A)$ & $1.63 \pm 0.16$ & $1.56 \pm 0.11$ & 0.743 & 0.034 & 0.808 \\
\hline PPAR $($ PPARD) & $0.36 \pm 0.04$ & $0.48 \pm 0.07$ & 0.114 & 0.175 & 0.259 \\
\hline SREBPIc (SREBF1) & $0.92 \pm 0.10$ & $1.12 \pm 0.14$ & 0.238 & 0.028 & 0.840 \\
\hline$S R E B P 2(S R E B F 2)$ & $1.43 \pm 0.15$ & $1.86 \pm 0.23$ & 0.127 & 0.266 & 0.216 \\
\hline ChREBP $(C R E B B P)$ & $1.02 \pm 0.19$ & $0.99 \pm 0.15$ & 0.906 & -0.040 & 0.859 \\
\hline TAG synthesis & $n=10$ & $n=15$ & & & \\
\hline GPAT1 (GPAM) & $2.55 \pm 0.23$ & $1.81 \pm 0.25$ & 0.050 & -0.666 & 0.002 \\
\hline$D G A T 1$ & $1.89 \pm 0.19$ & $1.77 \pm 0.20$ & 0.667 & 0.079 & 0.683 \\
\hline$D G A T 2$ & $0.31 \pm 0.05$ & $0.25 \pm 0.06$ & 0.509 & -0.103 & 0.671 \\
\hline TAG lipolysis & $n=15$ & $n=8$ & & & \\
\hline$L P L$ & $0.50 \pm 0.08$ & $0.62 \pm 0.11$ & 0.342 & 0.018 & 0.927 \\
\hline ATGL (PNPLA2) & $1.11 \pm 0.17$ & $2.52 \pm 0.60$ & 0.052 & 0.522 & 0.007 \\
\hline HSL (LIPE) & $0.44 \pm 0.19$ & $0.74 \pm 0.21$ & 0.329 & 0.130 & 0.515 \\
\hline
\end{tabular}

Values are presented as mean $\pm \mathrm{SEM}$

The italic entries are all gene symbols

${ }^{a} p$ value for difference between mild-IR and high-IR group, Student's $t$ test for unpaired samples

${ }^{\mathrm{b}} p$ value for multiple linear regression

$m$ CPT1b, muscle CPT1B; SE $\beta$, standardised $\beta$ coefficient for HOMA-IR, adjusted for sex and BMI pool, since it has been shown that FA composition of skeletal muscle reflects dietary FA composition [37]. However, data related to odd-chain FA metabolism in skeletal muscle are currently lacking and more research is needed to unravel the role of odd-chain FAs in intramyocellular lipid turnover and skeletal muscle IR. Moreover, it is important to note that the increased content of SFA in the high-IR group might be linked to an increased ceramide content and higher saturation in the longchain fatty acyl-CoA. It has been shown that increased levels of the SFA palmitate drive ceramide synthesis [38]. However, we did not measure skeletal muscle ceramide levels or expression of related genes in the present study. Finally, previous studies have shown that lower percentages of PUFA in the plasma membrane are associated with IR [39, 40]. However, in this study the percentages of total PUFAs in the muscle PL pool were comparable between groups. It is important to note that we have not specifically measured muscle membrane PL content but rather total muscle PL content. Since most PLs are located mainly in the plasma membrane, the reduced total PL content might reflect a lower absolute amount of PUFA in the muscle membrane fraction and might therefore contribute to the worsening of IR in individuals with high-IR.
A limitation of the present study is that we did not perform a hyperinsulinaemic-euglycaemic clamp test to assess insulin sensitivity. Rather, we divided groups based on a surrogate marker of whole-body insulin sensitivity, namely HOMAIR. Nevertheless, previous studies have shown strong correlations between HOMA-IR and peripheral insulin sensitivity, as measured by the gold-standard hyperinsulinaemiceuglycaemic clamp [41]. Importantly, in this study individuals in the high-IR group had a significantly lower postprandial net glucose uptake across forearm muscle as compared with the individuals with mild-IR, despite having significantly higher postprandial plasma insulin concentrations. Since skeletal muscle accounts for approximately $80 \%$ of insulin-mediated glucose uptake in humans [42], these data clearly indicate a more pronounced skeletal muscle IR in the individuals with high-IR as compared with those with mild-IR.

In conclusion, increased skeletal muscle VLDL-TAG extraction in the postprandial state and higher saturation of the intramuscular NEFA pool are associated with more pronounced IR. These data support an important role for disturbances in skeletal muscle FA handling in the progression of whole-body IR. 
Acknowledgements We would like to thank all participants for taking part in this study. We thank A. van Hees, A. Jans, E. Konings and C. Moors for their contribution to the clinical studies and J. Stegen, W. Sluijsmans, H. Aydeniz, R. Jacobs, A. Gijsen, Y. Essers, P. Schoffelen and L. Wouters for their excellent analytical and technical support (all from the Department of Human Biology, NUTRIM School of Nutrition and Translational Research in Metabolism, Maastricht University Medical Center ${ }^{+}$, the Netherlands).

Funding This study was supported by internal resources from Maastricht University.

Duality of interest The authors declare that there is no duality of interest associated with this manuscript.

Contribution statement BWvdK, GHG, JWJ and EEB designed the study. BWvdK and GHG conducted the research, BWvdK analysed the data and performed statistical analysis and BWvdK wrote the manuscript. All authors contributed to revising the article critically for important intellectual content and gave their final approval of the version to be published. EEB is the guarantor of this work.

Open Access This article is distributed under the terms of the Creative Commons Attribution 4.0 International License (http:// creativecommons.org/licenses/by/4.0/), which permits unrestricted use, distribution, and reproduction in any medium, provided you give appropriate credit to the original author(s) and the source, provide a link to the Creative Commons license, and indicate if changes were made.

\section{References}

1. Stinkens R, Goossens GH, Jocken JWE, Blaak EE (2015) Targeting fatty acid metabolism to improve glucose metabolism. Obes Rev 16:715-757

2. Goossens GH (2008) The role of adipose tissue dysfunction in the pathogenesis of obesity-related insulin resistance. Physiol Behav 94:206-218

3. Ebbert J, Jensen M (2013) Fat depots, free fatty acids, and dyslipidemia. Nutrients 5:498-508

4. Mittendorfer B (2011) Origins of metabolic complications in obesity: adipose tissue and free fatty acid trafficking. Curr Opin Clin Nutr Metab 14:535-541

5. Mensink M, Blaak EE, van Baak MA et al (2001) Plasma free fatty acid uptake and oxidation are already diminished in subjects at high risk for developing type 2 diabetes. Diabetes 50:2548-2554

6. Dubé JJ, Coen PM, DiStefano G et al (2014) Effects of acute lipid overload on skeletal muscle insulin resistance, metabolic flexibility, and mitochondrial performance. Am J Physiol Endocrinol Metab 307:E1117-E1124

7. Schrauwen P, Schrauwen-Hinderling V, Hoeks J, Hesselink MKC (2010) Mitochondrial dysfunction and lipotoxicity. Biochim Biophys Acta 1801:266-271

8. Coen PM, Goodpaster BH (2012) Role of intramyocelluar lipids in human health. Trends Endocrinol Metab 23:391-398

9. Samuel VT, Shulman GI (2012) Mechanisms for insulin resistance: common threads and missing links. Cell 148:852-871

10. Blaak EE, Wagenmakers AJ, Glatz JF et al (2000) Plasma FFA utilization and fatty acid-binding protein content are diminished in type 2 diabetic muscle. Am J Physiol Endocrinol Metab 279:E146E154

11. Bickerton AST, Roberts R, Fielding BA et al (2008) Adipose tissue fatty acid metabolism in insulin-resistant men. Diabetologia 51: $1466-1474$
12. Jocken JWE, Goossens GH, van Hees AMJ et al (2008) Effect of beta-adrenergic stimulation on whole-body and abdominal subcutaneous adipose tissue lipolysis in lean and obese men. Diabetologia 51:320-327

13. Hodson L, Bickerton AST, McQuaid SE et al (2007) The contribution of splanchnic fat to VLDL triglyceride is greater in insulinresistant than insulin-sensitive men and women: studies in the postprandial state. Diabetes 56:2433-2441

14. Riemens SC, Sluiter WJ, Dullaart RP (2000) Enhanced escape of non-esterified fatty acids from tissue uptake: its role in impaired insulin-induced lowering of total rate of appearance in obesity and Type II diabetes mellitus. Diabetologia 43:416-426

15. Nielsen S, Karpe F (2012) Determinants of VLDL-triglycerides production. Curr Opin Lipidol 23:321-326

16. Choi SH, Ginsberg HN (2011) Increased very low density lipoprotein (VLDL) secretion, hepatic steatosis, and insulin resistance. Trends Endocrinol Metab 22:353-363

17. Bickerton AST, Roberts R, Fielding BA et al (2007) Preferential uptake of dietary fatty acids in adipose tissue and muscle in the postprandial period. Diabetes 56:168-176

18. Ruge T, Hodson L, Cheeseman J et al (2009) Fasted to fed trafficking of fatty acids in human adipose tissue reveals a novel regulatory step for enhanced fat storage. J Clin Endocrinol Metab 94:17811788

19. van Hees AMJ, Jans A, Hul GB et al (2011) Skeletal muscle fatty acid handling in insulin resistant men. Obesity 19:1350-1359

20. Goossens G, Moors C, Jocken J et al (2016) Altered skeletal muscle fatty acid handling in subjects with impaired glucose tolerance as compared to impaired fasting glucose. Nutrients 8:164-165

21. Jans A, Konings E, Goossens GH et al (2012) PUFAs acutely affect triacylglycerol-derived skeletal muscle fatty acid uptake and increase postprandial insulin sensitivity. Am J Clin Nutr 95:825-836

22. Bergström J, Hermansen L, Hultman E, Saltin B (1967) Diet, muscle glycogen and physical performance. Acta Physiol Scand 71: $140-150$

23. Bosma M, Kersten S, Hesselink MKC, Schrauwen P (2012) Reevaluating lipotoxic triggers in skeletal muscle: relating intramyocellular lipid metabolism to insulin sensitivity. Prog Lipid Res 51:36-49

24. Moors CCM, van der Zijl NJ, Diamant M et al (2012) Impaired insulin sensitivity is accompanied by disturbances in skeletal muscle fatty acid handling in subjects with impaired glucose metabolism. Int J Obes (Lond) 36:709-717

25. Samuel VT, Petersen KF, Shulman GI (2010) Lipid-induced insulin resistance: unravelling the mechanism. Lancet 375:2267-2277

26. Hiukka A, Fruchart-Najib J, Leinonen E et al (2005) Alterations of lipids and apolipoprotein CIII in very low density lipoprotein subspecies in type 2 diabetes. Diabetologia 48:1207-1215

27. Kersten S (2014) Physiological regulation of lipoprotein lipase. Biochim Biophys Acta 1841:919-933

28. Heath RB, Karpe F, Milne RW et al (2003) Selective partitioning of dietary fatty acids into the VLDL TG pool in the early postprandial period. J Lipid Res 44:2065-2072

29. Heath RB, Karpe F, Milne RW et al (2007) Dietary fatty acids make a rapid and substantial contribution to VLDL-triacylglycerol in the fed state. Am J Physiol Endocrinol Metab 292:E732-E739

30. Yost TJ, Jensen DR, Haugen BR, Eckel RH (1998) Effect of dietary macronutrient composition on tissue-specific lipoprotein lipase activity and insulin action in normal-weight subjects. Am J Clin Nutr 68:296-302

31. Goldberg IJ, Eckel RH, Abumrad NA (2009) Regulation of fatty acid uptake into tissues: lipoprotein lipase- and CD36-mediated pathways. J Lipid Res 50(Suppl):S86-S90

32. Sparks LM, Bosma M, Brouwers B et al (2014) Reduced incorporation of fatty acids into triacylglycerol in myotubes from obese individuals with type 2 diabetes. Diabetes 63:1583-1593 
33. Montell E, Turini M, Marotta M et al (2001) DAG accumulation from saturated fatty acids desensitizes insulin stimulation of glucose uptake in muscle cells. Am J Physiol Endocrinol Metab 280:E229 E237

34. Perreault L, Bergman BC, Hunerdosse DM et al (2009) Inflexibility in intramuscular triglyceride fractional synthesis distinguishes prediabetes from obesity in humans. Obesity 18:1524-1531

35. Forouhi NG, Koulman A, Sharp SJ, Imamura F (2014) Differences in the prospective association between individual plasma phospholipid saturated fatty acids and incident type 2 diabetes: the EPICInterAct case. Lancet Diabetes Endocrinol 2:810-818

36. Jenkins B, West J, Koulman A (2015) A review of odd-chain fatty acid metabolism and the role of pentadecanoic acid (C15:0) and heptadecanoic acid (C17:0) in health and disease. Molecules 20: $2425-2444$

37. Andersson A, Nälsén C, Tengblad S, Vessby B (2002) Fatty acid composition of skeletal muscle reflects dietary fat composition in humans. Am J Clin Nutr 76:1222-1229
38. Chaurasia B, Summers SA (2015) Ceramides - lipotoxic inducers of metabolic disorders. Trends Endocrinol Metab 26:538-550

39. Borkman M, Storlien LH, Pan DA et al (1993) The relation between insulin sensitivity and the fatty-acid composition of skeletal-muscle phospholipids. N Engl J Med 328:238-244

40. Baur LA, O Connor J, Pan DA et al (1998) The fatty acid composition of skeletal muscle membrane phospholipid: its relationship with the type of feeding and plasma glucose levels in young children. Metabolism 47:106-112

41. Bonora E, Targher G, Alberiche $\mathrm{M}$ et al (2000) Homeostasis model assessment closely mirrors the glucose clamp technique in the assessment of insulin sensitivity: studies in subjects with various degrees of glucose tolerance and insulin sensitivity. Diabetes Care 23:57-63

42. DeFronzo RA, Jacot E, Jequier E et al (1981) The effect of insulin on the disposal of intravenous glucose. Results from indirect calorimetry and hepatic and femoral venous catheterization. Diabetes 30:1000-1007 